\title{
Consumption Pattern of Dried Traditional African Vegetables among Rural Households in Tanzania
}

\author{
Wilbon Cheruiyot Yegon ${ }^{*}$, Oscar Ayuya Ingasia1, Justus Ochieng² \\ ${ }^{1}$ Department of Agricultural Economics and Agribusiness Management, Egerton University, Njoro, Kenya \\ ${ }^{2}$ World Vegetable Centre, Duluti, Arusha, Tanzania \\ Email: *yegonwilbon@gmail.com
}

How to cite this paper: Yegon, W. C., Ingasia, O. A., \& Ochieng, J. (2021). Consumption Pattern of Dried Traditional African Vegetables among Rural Households in Tanzania. Modern Economy, 12, 1059-1071.

https://doi.org/10.4236/me.2021.125054

Received: April 10, 2021

Accepted: May 25, 2021

Published: May 28, 2021

Copyright $\odot 2021$ by author(s) and Scientific Research Publishing Inc. This work is licensed under the Creative Commons Attribution International License (CC BY 4.0).

http://creativecommons.org/licenses/by/4.0/ (c) (i) Open Access

\begin{abstract}
Vegetables are known to be nutritious and form part of almost every meal in an African set up. However, they are known to be perishable and seasonal thus scarce during dry period. Drying helps extend their shelf life. The main objective of the study was to determine consumption pattern of dried traditional vegetables (TAVs) in semi-arid rural households. Dried TAVs by open sun drying and solar drying were considered. Cross-section data collected in 2016 among 244 respondents in Dodoma and Singida region through random sampling using semi-structured questionnaire was utilized. Ordered bivariate probit was estimated using STATA software. The results showed that access to information on drying, gender, presence of adults above 64 years, adults between 15 - 64 years, children between 5 - 14 and 0 - 4 years was significant. The information is useful in planning trainings and in determining the consumer segment to target. Strategies that would enhance information access are highly recommended.
\end{abstract}

\section{Keywords}

Open Sun Drying, Ordered Bivariate Probit, Solar Drying, TAVs

\section{Introduction}

Malnutrition is a major problem in developing countries (Holmer et al., 2013). Vegetable consumption plays a vital role in curbing malnutrition. World Health Organisation (WHO) recommends consumption of at least five portions of fruits and vegetables per day. Awareness of WHO recommendation influenced consumption of fruits and vegetables among college students (Alsunni \& Badar, 2015). It is also important in reducing the risk of chronic diseases among older 
people (Hazavehei \& Afshari, 2016; Li et al., 2012). Fruit and vegetable consumption has an association with emotional behavior. Its consumption is positively associated with happiness (Lesani et al., 2016). Studies have shown an inverse relationship between vegetable consumption and depression. In other words its consumption is likely to lower the levels of depression (Liu et al., 2016). Older people with low vegetable intake showed high level of depression (Payne et al., 2012).

Offering vegetables to children below four years before meals increases their consumption. Introduction of vegetables to children at a tender age is important in developing their consumption habits (Elsbernd et al., 2016). Children's early consumption of fruits and vegetables significantly determines mid-childhood consumption (Kong et al., 2016; Nicklaus \& Remy, 2013). Awareness creation is important in enhancing purchase and consumption of solar dried vegetables (retained high nutrients and of high quality) (Kessy et al., 2018). Individual perception, socio-economic and environmental factors are key determinants in purchase, preparation and consumption of vegetables (Kessy et al., 2018; Graham et al., 2013). Ease of cooking and training on nutritional value of vegetable enhance their consumption among school going children (Jarpe-Ratner et al., 2016). Income is also directly associated with vegetable consumption (Middaugh et al., 2012).

Despite the critical role played by vegetables they suffer from seasonality and perishability. Drying thus offers an alternative solution. For ease of preservation, transport or storage drying is important. Pretreatment before drying helps reduce nutrient loss (Oliveira et al., 2016). This study therefore focused on consumption of dried vegetables dried by open sun drying and solar drying. Open sun-dried leaves tend to dry non-uniformly and lose nutrients (namely vitamin A and C) through exposure to direct sunlight, decreasing end product quality (Musa \& Ogbadoyi, 2012). Solar dried on the other hand is of high quality (high nutrient retention) and dry uniformly (Ahmed et al., 2013). The current study focused on consumption of both open sun dried and solar dried TAVs as they both contribute significantly to food nutrition security. The modeling contributes to the body of knowledge in the study of vegetable consumption.

\section{Methodology}

\subsection{Study Area}

This study was based on rural households in Tanzania officially referred to as United Republic of Tanzania (URT). Tanzania is located between $1^{\circ}$ and $12^{\circ}$ south of the equator and between $29^{\circ}$ and $41^{\circ}$ east of Greenwich meridian (Nyomora \& Mwasha, 2006). This study focused on three districts of Mpwapwa and Kongwa (Dodoma region) and Iramba district (Singida region). The two districts in Dodoma were purposively selected because the World Vegetable Center had initially conducted trainings on vegetables drying. In addition, Iramba District was selected as control because it was not reached before by the 
same intervention. The three districts forms part of the semi-arid central zone of Tanzania, which experiences low rainfall in short seasons which are often erratic, with fairly widespread drought in one year out of four. Total rainfall ranges from $500 \mathrm{~mm}$ to $800 \mathrm{~mm}$ per annum (URT, 2016). Moreover, temperature differences are observed between day and night and may be very high, with hot afternoons going up to $35^{\circ} \mathrm{C}$ and chilly nights going down to $10^{\circ} \mathrm{C}$.

\subsection{Sampling Procedure}

A multistage sampling procedure was used to obtain rural consumers to participate in the survey. In the first stage, purposive sampling technique was adopted to identify the districts based on interactions with vegetables stakeholders. Divisions were purposively selected, that is, one in each district. Two wards in each division were also purposively selected and finally the villages were randomly selected. The villages are the lowest administrative unit in the country and were therefore suitable as primary sampling unit. Two villages were randomly selected from each ward.

Within each selected village, twenty households were randomly selected to give a total of 240 consumers. The selected households were visited between July and August 2016 by six trained enumerators. The respondents were either household head or the spouse of the head because they are mainly involved in food purchase decision making and preparation. From the sampling design 240 respondents were to be interviewed, that is, 80 in each of the three districts. However, 81, 81 and 82 respondents were interviewed in Mpwapwa, Kongwa and Iramba respectively giving a total of 244 respondents. Data was collected through personal interviews using pre-tested questionnaires by six trained enumerators. The data collected includes socio-economic information, information on awareness and demand for dried vegetables; product attributes on Likert scale, consumers' attitudes, perceptions and consumption.

\subsection{Econometric Modeling}

This was modeled by bivariate ordered probit model. The model offers an estimate between correlations of errors (Dumortier et al., 2017). Understanding consumption frequency was important in deciding the best course of action.

Consumption of solar dried TAVs and open sun dried TAVs were expressed as a frequency of consumption. The frequency of consumption was the dependent variable measured as an ordinal variable. In this study, we had five categories 1) more than twice a day, 2) once a day, 3) 1 - 2 times a week, 4) 3 - 5 times a week, 5) once a month. The consumption of the two types of dried vegetables can be estimated simultaneously by a bivariate ordered probit. Consumption frequencies of solar dried TAVs and open sun dried TAVs might not be independent thus make bivariate ordered probit suitable.

The bivariate ordered probit is a development of univariate ordered probit model. Univariate model can be expressed as: 


$$
y_{i}^{\bullet}=\beta X_{i}+\varepsilon_{i}
$$

where $y_{i}^{\bullet}$ is unobserved latent utility of consumption of dried vegetables;

$\beta$ is a vector of coefficients to be estimated;

$X_{i}$ is a vector of explanatory variables;

$\varepsilon_{i}$ is the error term.

In this study the consumption frequencies are observed discrete categories denoted as $\varepsilon_{i}$;

$$
y_{i}=\left\{\begin{array}{cc}
1 & y_{i}^{\bullet} \leq u_{1} \\
2 & u_{1}<y_{i}^{\bullet} \leq u_{2} \\
\vdots & \\
l & y_{i}^{\bullet}>u_{l}
\end{array}\right.
$$

where:

$u_{i}$ is unknown cut-off of the latent utility to be estimated;

$l$ is the number of frequency categories. For this case $l=5$.

If the error term follows a standard normal distribution then we have;

$$
\begin{aligned}
& p\left(y_{i}=1\right)=\int_{-\infty}^{-\beta x_{i}} \phi\left(\varepsilon_{i}\right) \mathrm{d} \varepsilon_{i}=\varphi\left(-\beta x_{i}\right) \\
& p\left(y_{i}=2\right)=\int_{-\beta x_{i}}^{u_{1}-\beta x_{i}} \phi\left(\varepsilon_{i}\right) \mathrm{d} \varepsilon_{i}=\varphi\left(u_{1}-\beta x_{i}\right)-\varphi\left(-\beta x_{i}\right) \\
& p\left(y_{i}=3\right)=\int_{u_{2}-\beta x_{i}}^{u_{3}-\beta x_{i}} \phi\left(\varepsilon_{i}\right) \mathrm{d} \varepsilon_{i}=\varphi\left(u_{2}-\beta x_{i}\right)-\varphi\left(u_{1}-\beta x_{i}\right) \\
& p\left(y_{i}=4\right)=\int_{u_{3}-\beta x_{i}}^{u_{4}-\beta x_{i}} \phi\left(\varepsilon_{i}\right) \mathrm{d} \varepsilon_{i}=\varphi\left(u_{3}-\beta x_{i}\right)-\varphi\left(u_{2}-\beta x_{i}\right) \\
& p\left(y_{i}=5\right)=\int_{u_{4}-\beta x_{i}}^{\infty} \phi\left(\varepsilon_{i}\right) \mathrm{d} \varepsilon_{i}=1-\varphi\left(u_{4}-\beta x_{i}\right)
\end{aligned}
$$

where:

$\phi$ is the standard normal probability density;

$\varphi$ is the cumulative distribution function;

$\beta$ are unknown parameters to estimate;

$\varepsilon_{i}$ is the error term.

For open sun dried TAVs and solar dried TAVs the probabilities can be given as;

$$
\begin{aligned}
& P\left(y_{1 i}=h, y_{2 i}=j\right) \\
& =\int_{u_{2(j-1)}-\beta_{2} x_{2 i}}^{u_{2 j}-\beta_{2} x_{2 i}} \int_{u_{1(h-1)}-\beta_{1} x_{1 i}}^{u_{1 h}-\beta_{1} x_{1 i}} \phi_{2}\left(\varepsilon_{1 i}, \varepsilon_{2 i}, \sigma\right) \mathrm{d} \varepsilon_{1 i} \mathrm{~d} \varepsilon_{2 i} \\
& =\varphi_{2}\left(u_{1 h}-\beta_{1} x_{1 i}, u_{2 j}-\beta_{2} x_{2 i}, \sigma\right)-\varphi_{2}\left(u_{1(h-1)}-\beta_{1} x_{1 i}, u_{2 j}-\beta_{2} x_{2 i}, \sigma\right) \\
& -\varphi_{2}\left(u_{1 h}-\beta_{1} x_{1 i}, u_{2(j-1)}-\beta_{2} x_{2 i}, \sigma\right)+\varphi_{2}\left(u_{1(h-1)}-\beta_{1} x_{1 i}, u_{2(j-1)}-\beta_{2} x_{2 i}, \sigma\right)
\end{aligned}
$$

where $y_{1 i}$ is the observed frequency of consumption of open sun dried vegetable $(h=1, \cdots, 5)$ and $y_{2 i}$ is the observed frequency of consumption of solar dried vegetable $(j=1, \cdots, 5)$;

$\phi_{2}$ is the standard bivariate normal probability density;

$\varphi_{2}$ is the cumulative distribution function;

$\sigma$ is an unknown correlation between $\varepsilon_{1 i}$ and $\varepsilon_{2 i}$ to be estimated. 
Maximum likelihood will be used to estimate $\beta, \sigma, u_{h}, u_{j}, \varepsilon_{1 i}$ and $\varepsilon_{2 i}$ in this model

Marginal effects will be calculated to estimate how change in independent variable by one unit affects the change in consumption of solar dried TAVs and open sun dried TAVs (Table 1).

The empirical model was specified as below:

$$
\begin{aligned}
y_{1 i}, y_{2 i}= & \beta_{0}+\beta_{1} \text { EducYrs }+\beta_{2} \text { Age }+\beta_{3} \text { Infor }+\beta_{4} \text { Adult } 1+\beta_{5} \text { Adult } 2 \\
& +\beta_{6} \text { Child } 1+\beta_{7} \text { Child } 2+\beta_{8} \text { Drought }+\beta_{9} \text { INCOME }+\beta_{10} \text { HHpos } \\
& +\beta_{11} \text { Land } 1+\beta_{12} \text { Gender }+\beta_{13} \text { Land } 2+\beta_{14} \text { Kongwa }+\beta_{15} \text { Mpwapwa }
\end{aligned}
$$

\section{Results and Discussions}

\subsection{Summary Statistics for the Demand for Dried Traditional African Vegetables}

\begin{tabular}{|c|c|c|c|}
\hline Code & Variable & Measurement of variable & $\begin{array}{l}\text { Expected } \\
\text { sign }\end{array}$ \\
\hline \multicolumn{4}{|c|}{ Dependent variable } \\
\hline$y_{1 i}$ & $\begin{array}{l}\text { Frequency of consumption of } \\
\text { sun dried vegetables }\end{array}$ & $\begin{array}{c}1=\text { more than twice a day, } 2=\text { once a day } 3= \\
1-2 \text { times a week, } 4=3-5 \text { times a week, } \\
5=\text { once a month }\end{array}$ & \\
\hline$y_{2 i}$ & $\begin{array}{c}\text { Frequency of consumption of } \\
\text { solar dried TAVs }\end{array}$ & $\begin{array}{c}1=\text { more than twice a day, } 2=\text { once a day } 3= \\
1-2 \text { times a week, } 4=3-5 \text { times a week } \\
5=\text { once a month }\end{array}$ & \\
\hline \multicolumn{4}{|c|}{ Independent variables } \\
\hline Mpwapwa & Location & Dummy $(1=$ yes, $0=$ otherwise $)$ & $+/-$ \\
\hline Kongwa & Location & Dummy ( $1=$ yes, $0=$ otherwise $)$ & + \\
\hline Infor & $\begin{array}{l}\text { Access to solar dried } \\
\text { information }\end{array}$ & Dummy ( $1=$ yes, $0=$ otherwise $)$ & + \\
\hline Land 1 & Cultivate own land & Continuous & - \\
\hline Land2 & Cultivate leased land & Continuous & - \\
\hline Age & Age of respondent & Continuous & $+1-$ \\
\hline Gender & Gender of respondent & Dummy $(1=$ male, $0=$ otherwise $)$ & - \\
\hline HHpos & $\begin{array}{c}\text { Position of respondent in the } \\
\text { household }\end{array}$ & Head $(1=$ yes, $0=$ otherwise $)$ & $+1-$ \\
\hline EducYrs & Education level of respondent & Continuous & + \\
\hline CHILD1 & Children below 4 years & Continuous & + \\
\hline CHILD2 & Children between 5 - 14 years & Continuous & + \\
\hline Adult1 & Adults between 15 - 64 years & Continuous & $+/-$ \\
\hline Adult2 & Adults above 64 years & Continuous & $+1-$ \\
\hline INCOME & Gross income & Continuous & + \\
\hline
\end{tabular}

The summary statistics for demand for dried traditional African vegetables are

Table 1. Variables used to analyze consumption pattern of dried TAVs. 
as presented in Table 2. The results indicated that all the respondents were aware of open sun dried TAVs. Drying of vegetables through open sun drying is a common practice as evidenced by consumption length with a respondent having consumed it for 84 years. Since it is a common practice, awareness of open sun dried TAVs was expected to be high. The results indicated that $63.5 \%$ of respondents were not aware of availability of solar dried vegetable while only $36.5 \%$ were aware. Solar drying technology is a new practice thus this explains why $63.5 \%$ were not aware. Malik et al. (2013) point out that creating consumer awareness plays a critical role in stimulating buyers' interests in a product. Out of a total of 89 respondents who were aware of solar dried TAVs, $64.0 \%$ had consumed while $36 \%$ have not. Awareness creates demand and since solar dried TAVs are of high quality this explains why a high percentage of those who were aware had consumed it. Consumers also respond differently to technology. However, other factors like attitudes and perceptions influence consumption. Kessy et al. (2018) established that attitudes and perceptions played a significant part in consumption of solar dried TAVs.

Consumers had various reasons for consuming dried vegetables as shown in Table 3. Climate change explains why about $18.03 \%$ of the respondents consumed dried vegetables. The study area receives erratic rainfall, also considered semi-arid thus production of green vegetables throughout the year is not possible for low income rural households. Vegetable was part of almost every meal, this means high demand. Dried vegetables can be stored for long thus this explains their consumption during dry period or its consumption based on climate change. The intertwining of dried vegetables being a traditional food and climate change was the major reason for respondents consuming it $(25.82 \%$ of the respondents). This implies consumers are aware of climatic changes and have put in place measures by drying vegetables to ensure their availability even during

Table 2. Consumer awareness of dried and consumption of solar dried TAVs.

\begin{tabular}{cccc}
\hline Variable & Description & Frequency & Percentage \\
\hline Aware of open sun dried & Yes & 244 & 100 \\
Aware of solar dried & No & 155 & 63.52 \\
Aware and consumed solar dried & Yes & 89 & 36.48 \\
& No & 32 & 64 \\
\hline
\end{tabular}

Table 3. Reason for consuming dried vegetables.

\begin{tabular}{cc}
\hline Consumption reason & Percentage \\
Traditional food & 7.79 \\
Traditional food and climate change & 25.82 \\
Climate change & 18.03 \\
Climate change and no alternative & 5.74 \\
\hline
\end{tabular}


dry seasons. Consumers also have preference for dried vegetables since only $5 \%$ stated that a combination climate change and lack of alternative was the reason for consuming dried vegetables.

\subsection{Summary of Consumption Pattern}

From Table 4, a total of 242 respondents consumed open sun dried TAVs while two did not consume during the survey period representing $99.2 \%$ of the sampled respondents. A majority, 39.3\% and 37.6\% consumed it at least $1-2$ times a day and at least 3-5 times a week respectively. This was due to the availability of open sun dried TAVs in the area of study. The results also indicated that very few respondents rarely consume it with $3.7 \%$ of the respondents consuming it at least once a month. This can be attributed to consumer awareness. On the other hand, solar dried TAVs is a new product thus 57 respondents had consumed representing $23.4 \%$ of all the respondents and $64.0 \%$ of those who were aware of its availability. A total of $33.3 \%$ have consumed it at least once a month. This signifies a high percentage of those who rarely consume it. However, $1.8 \%$ consumed it more than twice a day. The low consumption frequency can be attributed to low awareness and availability. This is consistent with the findings of Appleton et al. (2010) and Lynch et al. (2012) who argued that low awareness and availability were among major barriers to increasing vegetables and fruits consumption. A study by Mamiro et al. (2011) pointed out the need to create awareness in order to enhance the consumption of cowpea leaves among rural households.

\subsection{Estimation by Ordered Bivariate Probit}

The bivariate ordered probit was used to analyze consumption pattern and frequency for both solar and open sun dried TAVs. The model was suitable because it allowed for joint modelling of the two consumption frequencies and thus offered simultaneous results. Consumption frequencies of sun dried and solar dried TAVs are dependent variables. Pre-diagnostic tests were done before carrying out econometric analysis. Multicollinearity is a serious problem in any econometric analysis, therefore, variance inflation factor test was done on continuous variables and pairwise correlation on categorical variables. However,

Table 4. Consumption frequency of sun and solar dried TAVs.

\begin{tabular}{cccccc}
\hline $\begin{array}{c}\text { Consumption frequency of open sun } \\
\text { dried TAVs }(\mathbf{n}=\mathbf{2 4 2})\end{array}$ & \multicolumn{3}{c}{$\begin{array}{c}\text { Consumption frequency of solar } \\
\text { dried TAVs }(\mathbf{n}=57)\end{array}$} \\
\hline $\begin{array}{c}\text { Frequency } \\
\text { once a month }\end{array}$ & $\begin{array}{c}\text { Freq. } \\
\text { - Percentage }\end{array}$ & 3.7 & Frequency & Freq. & Percentage \\
3 - 5 times a week & 91 & 37.6 & $3-5$ times a week & 14 & 24.6 \\
$1-2$ times a day & 95 & 39.3 & $1-2$ times a day & 19 & 33.3 \\
once a day & 21 & 8.7 & once a day & 4 & 7.0 \\
more than twice a day & 26 & 10.7 & more than twice a day & 1 & 1.8 \\
\hline
\end{tabular}


from the results it showed that multicollinearity was not a problem. The results of pre diagnostic tests are as presented in Table 5.

\subsection{Consumption Pattern Estimated Ordered Bivariate Probit}

Table 6, represents the estimated coefficients for the model. Estimated coefficients and standard errors are reported for consumption of each of the traditional African dried vegetables. From the results there is an overall goodness fit with appropriate chi-square. The model strongly fits and is statistically significant prob. $>$ chi $^{2}=0.000$ and a log likelihood of -112.313 .

For open sun dried TAVs gender of the respondent was significant at $10 \%$ significance level. Males were less likely to consume open sun dried TAVs. Females were more likely to consume open sun dried TAVs. Females are mainly involved in food preparation including drying and cooking. This can also be attributed to the role women play in food purchase and food preparation. The results concur with the findings of Ngigi (2010) who argued that women were major purchasers of vegetables. Presence of adults above 64 years was also significant at $10 \%$. This is an age bracket of old people. Old people consider open sun dried TAVs as their traditional food; it is what they have grown up consuming. They tend to be conservative in nature and reluctant to new products. They would therefore, prefer to frequently consume open sun dried TAVs as opposed to solar dried TAVS. Old people tend to stay at home thus have limited information on solar dried TAVs. However, some who are aware cannot afford as they have a lot of financial needs to meet.

Market quality attributes were significant at $1 \%$. Market quality attributes, that is, price, drying method, colour, freshness, nutritional value, packaging and hygiene were more likely to influence consumption frequency of open sun dried TAVs. This can be attributed to affordability and storability. Consumers develop

Table 5. Variance inflation factor test results for multicollinearity.

\begin{tabular}{ccc}
\hline Variable & VIF & 1/VIF \\
Age of the respondent & 2.8 & 0.3571 \\
Years consuming dried TAVs & 2.27 & 0.4398 \\
Number of adults above 64 years of age & 1.52 & 0.6577 \\
Number of adults between 15 - 64 years of age & 1.21 & 0.8291 \\
Years of schooling & 1.2 & 0.8322 \\
Income in us dollars & 1.2 & 0.8364 \\
Cultivate own land & 1.17 & 0.8553 \\
Cultivate leased land & 1.1 & 0.9054 \\
Presence of children below 4 years & 1.1 & 0.9091 \\
Presence of children between 4 - 14 years & 1.05 & 0.9520
\end{tabular}

Note: VIF = variance inflation factor. 
Table 6. Consumption frequencies of sun and solar dried TAVs estimated by means of a bivariate ordered probit model.

\begin{tabular}{|c|c|c|c|c|}
\hline \multicolumn{3}{|c|}{ Open sun dried TAVs } & \multicolumn{2}{|c|}{ Solar dried dried TAVs } \\
\hline Variable & Coefficient & Std. Error & Coefficient & Std. Error \\
\hline \multicolumn{5}{|l|}{ Socio-economic characteristics } \\
\hline Age of household head (years) & -0.020 & 0.019 & 0.030 & 0.020 \\
\hline Gender & $-0.923^{*}$ & 0.560 & $1.239^{*}$ & 0.741 \\
\hline Education in years & -0.025 & 0.080 & 0.498 & 0.386 \\
\hline \multicolumn{5}{|l|}{ Household size } \\
\hline Children below 4 years & 0.068 & 0.250 & $0.016^{*}$ & 0.092 \\
\hline Children between 5 - 14 years & -0.029 & 0.140 & $0.543^{* *}$ & 0.288 \\
\hline Adults between 15 - 64 years & 0.161 & 0.134 & $-0.320^{* *}$ & 0.161 \\
\hline Adults above 64 years & $0.748^{*}$ & 0.429 & -0.339 & 0.150 \\
\hline Household income in us dollars & 0.002 & 0.001 & 0.034 & 0.468 \\
\hline Cultivate own land Hactors & 0.011 & 0.054 & -0.050 & 0.057 \\
\hline Cultivate rented land in Hactors & -0.116 & 0.231 & 0.130 & 0.249 \\
\hline \multicolumn{5}{|l|}{ Attitudes and perceptions } \\
\hline (market quality attributes) & $0.799^{* * *}$ & 0.232 & $0.885^{\star * *}$ & 0.267 \\
\hline (product intrinsic qualities) & -0.015 & 0.197 & -0.290 & 0.214 \\
\hline \multicolumn{5}{|l|}{ Climatic characteristics } \\
\hline Prolonged drought & 0.194 & 0.341 & -0.256 & 0.372 \\
\hline \multicolumn{5}{|l|}{ Institutional characteristics } \\
\hline Mpwapwa & 0.550 & 0.475 & 0.710 & 0.507 \\
\hline Kongwa & 0.178 & 0.418 & 0.224 & 0.431 \\
\hline access to information & & & $-7.310^{\star * *}$ & 1.990 \\
\hline No of observations 55 & & & & \\
\hline Log likelihood & & & & \\
\hline Wald $\mathrm{ch}^{2}$ & & & & \\
\hline Prob. $>\mathrm{ch}^{2}$ & & & & \\
\hline
\end{tabular}

Note: ${ }^{* *}$ : significant at $1 \%$ level; ${ }^{* *}$ significant at $5 \%$ level; ${ }^{*}$ significant at $10 \%$. Iramba is the base. TAVs-traditional African vegetables.

trust on a product if regularly consumed. Considering open sun drying being old practice consumers have developed trust on it. Solar dried TAVs are relatively expensive compared to open sun dried. Consumers tend to make choices based on price thus the low cost of open sun dried TAVs can be driving factor. Boisseau (2019) identified high cost as a barrier to increasing consumption of vegetables among consumers with poor socio-economic background. These results confirm the findings of Davidson et al. (2012) who indicated that market quality attributes such as price, product freshness and nutritional value influenced consumers' purchasing decisions. 
For solar dried TAVs gender was significant at $10 \%$. Unlike for open sun dried males were more likely to frequently consume solar dried TAVs. In rural setting males have high purchasing power as they have resources like land ownership at their disposal. Males considering their roles in vegetable purchase and preparation have little knowledge on their quality thus would use price as an indicator of quality. Solar dried considering its high quality is a bit expensive compared to open sun dried TAVs. Presence of children of ages below 4 was significant at $10 \%$. This is an actively growing group therefore got high food demands. Solar dried TAVs also retained the green colour attractive to children. Presence of children between 5 and 14 years was also significant at 5\%. Households with children aged between 5 and 14 were more likely to consume solar dried TAVs more frequently. Solar dried TAVs are nutritious therefore a preference for this segment. The results are consistent with the findings of Albani et al. (2017) who points out the need for consuming vegetables among children aged between 5 and 14 years. Number of adults between 15 and 64 years was significant at 5\% significance level. Adults between 15 and 64 are less likely to consume it. They are likely to consume a variety of foods apart from vegetables thus reduction in their consumption frequency. This age category is active and productive. This implies they are able to produce the fresh vegetables. The results are consistent with findings of Senyolo et al. (2014) who argued that individual who produced fresh vegetables were less likely to purchase vegetables from the market.

Access to information on solar dried TAVs was very significant at $1 \%$. Majority of the respondents $(80 \%)$ had not accessed information on solar dried TAVs. Lack of information explains negative relationship on consumption frequency of solar dried TAVs and information access. This contradicts with the findings of Depositario et al. (2009) who argued that awareness of availability does not necessarily lead to increased consumption for a product.

\section{Conclusion}

Though open sun dried is of low quality as compared to solar dried TAVs, consumption of both types is important in combating food nutrition insecurity. Gender, product marketable characteristics and access to information are important in consumption of dried traditional African vegetables and highly influence the consumption frequency. Enhancing access to information and segmentation based on gender is important in increasing consumption of solar dried African vegetables which is of high quality. This study makes a significant contribution to the body of knowledge in understanding determinants of consumption of traditional African vegetables. However, a sample size of 244 is too small to make for generalization of the whole population. A bigger sample size is recommended for further studies. This was a cross-sectional study carried out towards the end of 2016. A longitudinal study is recommended to understand trends in consumption over time. 


\section{Acknowledgements}

This article is part of MSc thesis supported by Egerton University. We would like to thank world vegetable post-harvest program for allowing us to use their data.

We appreciate the support from the Regional Universities Forum for Capacity Building in Agriculture (RUFORUM) through "Transforming African Agricultural Universities to Meaningfully Contribute to Africa's Growth and Development (TAGDev)" program, Egerton University.

\section{Conflicts of Interest}

The authors declare no conflicts of interest regarding the publication of this paper.

\section{References}

Ahmed, N., Singh, J., Chauhan, H., Anjum, P. G. A., \& Kour, H. (2013). Different Drying Methods: Their Applications and Recent Advances. International Journal of Food Nutrition and Safety, 4, 34-42.

Albani, V., Butler, L. T., Traill, W. B., \& Kennedy, O. B. (2017). Fruit and Vegetable Intake: Change with Age across Childhood and Adolescence. British Journal of Nutrition, 117, 759-765. https://doi.org/10.1017/S0007114517000599

Alsunni, A. A., \& Badar, A. (2015). Fruit and Vegetable Consumption and Its Determinants among Saudi University Students. Journal of Taibah University Medical Sciences, 10, 201-207. https://doi.org/10.1016/j.jtumed.2014.11.003

Appleton, K. M., McGill, R., Neville, C., \& Woodside, J. V. (2010). Barriers to Increasing Fruit and Vegetable Intakes in the Older Population of Northern Ireland: Low Levels of Liking and Low Awareness of Current Recommendations. Public Health Nutrition, 13, 514-521. https://doi.org/10.1017/S1368980009991790

Boisseau, J. (2019). Home Availability of Vegetables, Barriers To Purchasing and Preparing Vegetables, and Vegetable Intake in a Sample of Primarily Low-Income, Hispanic Children. Master's Thesis, Austin, TX: University of Texas.

Davidson, K., Pan, M., Hu, W., \& Poerwanto, D. (2012). Consumers' Willingness to Pay for Aquaculture Fish Products vs. Wild-Caught Seafood-A Case Study in Hawaii. Aquaculture Economics \& Management, 16, 136-154.

https://doi.org/10.1080/13657305.2012.678554

Depositario, D. P. T., Nayga Jr., R. M., Wu, X., \& Laude, T. P. (2009). Effects of Information on Consumers' Willingness to Pay for Golden Rice. Asian Economic Journal, 23, 457-476. https://doi.org/10.1111/j.1467-8381.2009.02021.x

Dumortier, J., Evans, K. S., Grebitus, C., \& Martin, P. A. (2017). The Influence of Trust and Attitudes on the Purchase Frequency of Organic Produce. Journal of International Food \& Agribusiness Marketing, 29, 46-69. https://doi.org/10.1080/08974438.2016.1266565

Elsbernd, S. L., Reicks, M. M., Mann, T. L., Redden, J. P., Mykerezi, E., \& Vickers, Z. M. (2016). Serving Vegetables First: A Strategy to Increase Vegetable Consumption in Elementary School Cafeterias. Appetite, 96, 111-115. https://doi.org/10.1016/j.appet.2015.09.001

Graham, D. J., Pelletier, J. E., Neumark-Sztainer, D., Lust, K., \& Laska, M. N. (2013). Perceived Social-Ecological Factors Associated with Fruit and Vegetable Purchasing, Preparation, and Consumption among Young Adults. Journal of the Academy of Nu- 
trition and Dietetics, 113, 1366-1374. https://doi.org/10.1016/j.jand.2013.06.348

Hazavehei, S. M. M., \& Afshari, M. (2016). The Role of Nutritional Interventions in Increasing Fruit and Vegetable Intake in the Elderlies: A Systematic Review. Aging Clinical and Experimental Research, 28, 583-598. https://doi.org/10.1007/s40520-015-0454-9

Holmer, R., Linwattana, G., Nath, P., \& Keatinge, J. D. H. (Eds.) (2013). SEA VEG 2012: High Value Vegetables in Southeast Asia: Production, Supply and Demand. AVRDC-World Vegetable Center.

Jarpe-Ratner, E., Folkens, S., Sharma, S., Daro, D., \& Edens, N. K. (2016). An Experiential Cooking and Nutrition Education Program Increases Cooking Self-Efficacy and Vegetable Consumption in Children in Grades 3-8. Journal of Nutrition Education and Behavior, 48, 697-705. https://doi.org/10.1016/j.jneb.2016.07.021

Kessy, R., Ochieng, J., Afari-Sefa, V., Chagomoka, T., \& Nenguwo, N. (2018). Solar-Dried Traditional African Vegetables in Rural Tanzania: Awareness, Perceptions and Factors Affecting Purchase Decisions. Economic Botany, 72, 367-379. https://doi.org/10.1007/s12231-018-9434-2

Kong, K. L., Gillman, M. W., Rifas-Shiman, S. L., \& Wen, X. (2016). Mid-Childhood Fruit and Vegetable Consumption: The Roles of Early Liking, Early Consumption, and Maternal Consumption. Appetite, 105, 306-311. https://doi.org/10.1016/j.appet.2016.05.033

Lesani, A., Mohammadpoorasl, A., Javadi, M., Esfeh, J. M., \& Fakhari, A. (2016). Eating Breakfast, Fruit and Vegetable Intake and Their Relation with Happiness in College Students. Eating and Weight Disorders: Studies on Anorexia, Bulimia and Obesity, 21, 645-651. https://doi.org/10.1007/s40519-016-0261-0

Li, Y., Li, D., Ma, C. Y., Liu, C. Y., Wen, Z. M., \& Peng, L. P. (2012). Consumption of, and Factors Influencing Consumption of, Fruit and Vegetables among Elderly Chinese people. Nutrition, 28, 504-508. https://doi.org/10.1016/j.nut.2011.07.023

Liu, X., Yan, Y., Li, F., \& Zhang, D. (2016). Fruit and Vegetable Consumption and the Risk of Depression: A Meta-Analysis. Nutrition, 32, 296-302. https://doi.org/10.1016/j.nut.2015.09.009

Lynch, E. B., Holmes, S., Keim, K., \& Koneman, S. A. (2012). Concepts of Healthful Food among Low-Income African American Women. Journal of Nutrition Education and Behavior, 44, 154-159. https://doi.org/10.1016/j.jneb.2011.04.001

Malik, M. E., Ghafoor, M. M., Hafiz, K. I., Riaz, U., Hassan, N. U., Mustafa, M., \& Shahbaz, S. (2013). Importance of Brand Awareness and Brand Loyalty in Assessing Purchase Intentions of Consumer. International Journal of Business and Social Science, 4, 167-171.

Mamiro, P. S., Mbwaga, A. M., Mamiro, D. P., Mwanri, A. W., \& Kinabo, J. L. (2011). Nutritional Quality and Utilization of Local and Improved Cowpea Varieties in Some Regions in Tanzania. African Journal of Food, Agriculture, Nutrition and Development, 11, 4490-4506. https://doi.org/10.4314/ajfand.v11i1.65876

Middaugh, A. L., Fisk, P. S., Brunt, A., \& Rhee, Y. S. (2012). Few Associations between Income and Fruit and Vegetable Consumption. Journal of Nutrition Education and Behavior, 44, 196-203. https://doi.org/10.1016/j.jneb.2011.10.003

Musa, A., \& Ogbadoyi, E. O. (2012). Effect of Cooking and Sun Drying on Micronutrients, Anti Nutrients and Toxic Substances in Corchorus olitorius (Jute Mallow). Journal of Nutrition \& Food Sciences, 2, Article ID: 1000140. https://doi.org/10.4172/2155-9600.1000140

Ngigi, M. W. (2010). Urban Consumers' Perceptions and Willingness to Pay for Safety of Leafy Vegetables: The Case of Kale Consumers in Nairobi. Doctoral Dissertation, Nai- 
robi: University of Nairobi.

Nicklaus, S., \& Remy, E. (2013). Early Origins of Overeating: Tracking between Early Food Habits and Later Eating Patterns. Current Obesity Reports, 2, 179-184. https://doi.org/10.1007/s13679-013-0055-X

Nyomora, A. M., \& Mwasha, A. (2006). December. Indigenous Vegetable Crops of Tanzania: Research and Development Needs. ISHS Acta Horticulturae, 752, 609-614. https://doi.org/10.17660/ActaHortic.2007.752.115

Oliveira, S. M., Brandão, T. R., \& Silva, C. L. (2016). Influence of Drying Processes and Pretreatments on Nutritional and Bioactive Characteristics of Dried Vegetables: A Review. Food Engineering Reviews, 8, 134-163.

https://doi.org/10.1007/s12393-015-9124-0

Payne, M. E., Steck, S. E., George, R. R., \& Steffens, D. C. (2012). Fruit, Vegetable, and Antioxidant Intakes Are Lower in Older Adults with Depression. Journal of the Academy of Nutrition and Dietetics, 112, 2022-2027.

https://doi.org/10.1016/j.jand.2012.08.026

Senyolo, G. M., Wale, E., \& Ortmann, G. F. (2014). Consumers' Willingness-to-Pay for Underutilized Vegetable Crops: The Case of African Leafy Vegetables in South Africa. Journal of Human Ecology, 47, 219-227. https://doi.org/10.1080/09709274.2014.11906756

URT (2016). The United Republic of Tanzania. Dodoma Profile. 